\title{
Cytochrome C Oxidase
}

National Cancer Institute

\section{Source}

National Cancer Institute. Cytochrome C Oxidase. NCI Thesaurus. Code C26034.

An enzyme complex that plays a role in the electron transport cascade leading to ATP synthesis. 